\title{
Adoption of 'eco-advantage' by SMEs: emerging opportunities and constraints
}

\section{Abstract \\ Purpose}

Esty and Winston (2006) assert that businesses need to adopt 'eco-advantage.' This paper aims to explore the viability of SMEs achieving 'eco-advantage' by considering their understanding of sustainability issues, how they adopt and innovate in terms of sustainability and the benefits and obstacles they face.

\section{Methodology}

The research approach is exploratory, comprised of 15 SME embedded cases based in the UK. The cases are participants in short interventions in sustainable product and process design as a part of a university knowledge transfer project, representing the overall case. Cases are based on interviews with company participants and collaborating academics, supplemented by documentary and observational evidence.

\section{Findings}

The results build on the work on 'eco-advantage' (Esty and Winston, 2006), highlighting marketing, rather than compliance issues as a catalyst for change. The newly aware SME enters a development process which involves cumulative capabilities, gaining a nascent inner confidence, which includes espousing wider sustainable values and attempts at influencing internal and upstream practices in four dominant ways: use of alternative materials, enhancing recyclability (Sharma et al, 2010), local sourcing, and product to service shift (Maxwell and van der Vorst 2003), though few fully embrace strategic ecological and economic advantage. Obstacles include ephemerality of benefits (Shearlock et al, 2000) and practicalities of implementing internal and supply chain innovations.

\section{Implications}

The results reveal the scope and challenges for SMEs to adopt more sustainable practices, encompassing innovations and a broad set of capabilities. Further research points to the need to monitor benefits as well as inputs in evaluating sustainability improvements and consider longitudinal business sustainability issues

\section{Value}

The paper informs the emerging debate on sustainability in SMEs, providing a rich source of data to enhance the provision of business support and knowledge transfer activities, where a more holistic and customised approach is required to realise the real environmental and economic benefits accrued from implementing sustainable improvements. 


\section{Research paper}

Key words: SME, innovation, sustainable product and process; sustainable design; green marketing;

\section{Introduction}

Small and medium enterprises (SMEs) have generally been recognised as the seedbed of inventiveness, creativity and innovation (DTI, 1994). 'Green innovation' for SMEs could be seen to encompass the development of new, more environmentally friendly products, such as solar panels, changing processes to reduce waste, more energy efficient warehousing or a multitude of other sustainability initiatives. One particular viewpoint that links sustainability with competitive advantage is 'eco-advantage' (Esty and Winston 2006). Sustainability meaning...........Esty and Winston (2006) claim that businesses need to adopt 'eco-advantage', which takes the concept of sustainability in business further to include economic and stakeholder gain. The paper aims to explore SME managers' understanding of sustainability issues, adoption of innovative practices and the environmental and commercial benefits and obstacles associated with designing more sustainable 'SMEs are not nouns' then th where we (mainly environmental) products and processes, defined by Dangelico and Portrandolfo (2010:1609) perhaps they can't understand! as absolute green products that "contribute to the improvement of society or the environment" or relative green products which "reduce the harm they cause to society or environment". The paper addresses the following research questions.

1. What factors affect SMEs awareness and proclivity to adopt eco-advantage?

2. How can sustainability innovations be applied to small firms?

3. What issues emerge in implementing eco-advantage in SMEs?

The research is set within the context of a European Regional Development Funded project which is enabling SMEs to achieve sustainable design innovations. The research uses an embedded case study methodology aimed at exploring the experiences of some of these SMEs, otherwise considered 'hard to reach' (Cassells and Lewis 2011:187). The paper begins with a summary of the theoretical background, an explanation of the methodological approach, an illustrative table of findings and a discussion of the implications for theory and practice. It is acknowledged that the SMEs in the study are only at the beginning of their journey but their experience to date does identify key issues and provides a platform for future research.

\section{Theoretical background}

The dimensions of innovation are not solely product-oriented but are increasingly related to the manufacturing process, service delivery process, flexibility, adaptability and relationships with the 
customer/client; what Henry and Walker (1991) identified as incremental adjustments rather than new products. Most of the research into innovation has featured the larger organisation with the structures, processes and infrastructure necessary to encourage and sustain this activity and to apply the necessary expertise and resources. For Doyle (1998:208) "an innovative organisation is one which continually seeks new ways to better what it offers customers, rapidly processes these ideas and effectively implements the best of them." He suggests that the growth of the organisation is counter-productive to sustaining innovation, due to increasing role specialisation, compartmentalisation, low knowledge transfer about customer needs and the increasing attention to inputs over outputs. Successful innovation "requires commitment throughout the organisation" (Doyle, 1998:212) which may be achieved through new product teams (horizontal commitment and integration) and product champions, sponsors and orchestrators (hierarchical/vertical commitment) The other feature implicitly associated with the successful creative or innovative organisation is the capacity to acquire information, gain knowledge and experience and imbed this within the organisation. The role of organisational learning is offered as a possible explanation for the failure of SMEs to sustain their creativity/innovative advantage though they are still continuing to survive. However, Vernon et al (2003)suggests it is a lack of awareness that inhibits innovation.

One specific area of research and a source of increasing interest is that of sustainable, green or ecoinnovation (Baumann et al (2002), and there remains confusion over what is really meant by sustainable or green products. As Dangelico and Pujari (2010:472) assert "there is little knowledge on why and how companies integrate environmental sustainability into new product development". Correspondingly, little research has been undertaken into the SME sector in terms of SMEs' capability to innovate in respect of the 'green agenda'. The concept of 'eco-innovation' involves developing new products and processes which lower environmental impacts, whilst adding to customer and business values (James, 1997). Pujari (2006:76) found that the market performance of green products was enhanced when there was "cross-functional co-ordination between new product development professionals and environmental specialists...." For Jones and Harrison (2000) "Ecoinnovation is one step beyond Ecodesign and aims to develop new products and services that are not based on redesign or incremental changes to the existing product but rather on providing the consumer with the function that they require in the most Ecoefficient way." Although as van Hemel and Cramer (2002:452) argued, innovation opportunities were the key to ecodesign and can act "as an impetus for product innovation." The aim of this paper is to identify the capabilities, resources, knowledge and awareness from exogenous and endogenous sources that enable the SME to generate competitive advantage by addressing sustainability issues. 
Sustainability initiatives are transforming markets and distribution channels. The drivers for sustainability should not be seen solely as emanating from organisations, as there appears to have been an attendant shift in consumer attitudes with regard to green products, services and processes. The inter-play between consumer attitudes, supply chains and inter and intra organisational relationships is evidenced in both product and service markets. Although there are now an increasing number of conceptual studies on the link between sustainability and other disciplines, such as marketing (see Sharma et al, 2010), the majority, have focused on manufacturing and few have focused specifically on innovation or new product development (see for example Dangelico and Pontrandolfo, 2010). Indeed, Sharma et al (2010:330) argues that previous research "has been confined to disciplinary silos" and this is reflected in what is now categorised under the umbrella term 'green.'

Extant literature is moving on from generic issues of environmental management to a more valuebased, upstream approach to product and process that adds to economic and business sustainability. Dangelico and Pujari (2010) find that SMEs are likely to adopt green product/process innovation principally for strategic opportunity, while there is urgency to meet customer expectations and legal compliance (Esty and Winston, 2006) and where commercial goals are being pursued (van Hemel and Cramer, 2002). Understanding benefits, market and inter-organisational cooperation are supply chain priorities (Seuring and Muller, 2007) which impact upon sourcing and SME integration into the supply chain, but there is a lack of empirical research into the challenges of developing and marketing green products (Dangelico and Pujari, 2010) and little attention is paid to the SMEs' experience and business support needs in doing so (Shearlock et al, 2000).

\section{What is Eco-Advantage?}

Discussions of environmental sustainability in business have developed rapidly since the mid-1990s, in response to changes in government and international regulations, emerging compliance standards, opportunities for positive publicity and increasing expectations of customers and consumers (Melnyk et al, 2001; Sharma et al, 2010). Early focus on waste and energy reduction has developed into a more systems based approach to process improvements which incorporate environmental impact reduction drivers better into the economic or business sustainability imperatives. Discussions around the Triple Bottom line - economic, social and environmental contribution, and Corporate Social Responsibility (CSR) emphasise the further shift to incorporate social aspects into business strategy and practice (Erkko et al, 2005; Jenkins, 2009). 
Businesses are increasingly urged not to overlook CSR issues to save short term costs, since in the long term, exposure to risk could incur more substantial legal costs as well as loss of sales and reputation (Markley, 2007). Legrand et al (2010) posit that there is a trade-off between the potential rewards for actions undertaken against the threat of penalties for failure to act. In their study of restaurants, firms found to have already adopted green-thinking reduced waste and therefore cost; improved their community standing, thus securing more customers; and benefitted from better staff motivation. The alternative of negative brand image, loss of market share and threat of legal costs from non-compliance is to be avoided.

Furthermore, proactive businesses can achieve first mover benefits by adopting more sustainable practices, which in turn create competitive advantage that is hard for competitors to copy (Markley, 2007). According to Lynne (2008) leading companies meet both customer and environmental needs, build product platforms and loyalty based on environmental issues, add new values and innovations and develop the reputation of a trusted eco-brand. Examples might include Patagonia, Nike and Starbucks, Toyota, Ikea and, perhaps more controversially, BP (Esty and Winston, 2006:25).

Drivers of initiatives to reduce green impact are often considered to be regulatory and voluntary standards, industry-led strategy and government-led programmes (Cassells and Lewis, 2011). Meeting market needs, making money and capitalising on opportunity for the green pound is an alternative view. This commercial stimuli is found to be important in van Hemel and Cramer's study (2002). Eco-advantage, according to Lynne (2008:3) is therefore defined as a "joint and similar concern with both making money and doing the right thing", a strategy which involves compromise and a pragmatic approach to making improvements, without going to extremes. This is a definition which is potentially useful in an SME context and is used to inform this paper. Esty and Winston (2006) expand the idea in considerable detail, suggesting that leaders in the field take the need to address their environmental impact as a starting point for much more comprehensive strategic changes which positively affect their ability to compete and perception among stakeholders. Achieving eco-advantage is therefore a shift-change in strategic direction which at its least helps to reduce or counteract environmental impact, while satisfying the needs of the market. It is important to emphasise that Esty and Winston's (2006) concept includes an element of compromise and many of the proclaimed leaders are high environmental impact businesses but also organisations that are striving to make improvements, redress impactful activities and change values, both internally and externally, thus marking themselves out as industry leaders rather than attempting to eliminate impact. 


\section{How do leading firms achieve eco-advantage?}

Esty and Winston (2006) identify a number of key steps in progressing towards achieving ecoadvantage. Initially it is important to identify the various stakeholders and understand their disparate present and predicted needs. Stakeholders are defined as: rulemakers and watching bodies, opinion leaders and idea generators, business partners and competitors, consumers and the wider community and risk assessors/ investors (Esty and Winston, 2006:67). A thorough analysis of stakeholders leads to a good understanding of which are most important, how relationships can be built and dynamic, proactive strategies for meeting their needs. Indeed, Wilson et al (2010) discuss the complex nature of today's markets and argue for the central role of social partnerships involving a network of stakeholders.

Building on this knowledge enables proactive businesses to identify the 'downside' issues they must address, such as environmental and resource costs and risks; generate ideas for how they can manage the 'upside' issues such as revenue generation and intangibles like brand loyalty (ibid:103), and also develop a 'mindset' that takes into account clear objectives, targets and measures of improvement, as well as subjective values and the opinions of customers, wider stakeholders, and employees (ibid:165). According to Crittenden et al (2011) successful companies align sustainability to their marketing strategy, using a combination of what is referred to as 'company DNA', stakeholder involvement and performance management techniques. Sharma et al (2010:331) also emphasises the role of marketing and argues that internal and external marketing are key to the success of achieving sustainability. Maddock and Vitn (2010) go further, suggesting that companies that adopt sustainable practices also gain other unexpected benefits from what is otherwise a relatively low cost and easy to implement intervention. In the process of reducing environmental impact, materials, or energy usage other innovations can emerge, resulting in the generation of new product or new markets. For Esty and Winston (2006:205):

\footnotetext{
"Woveriders move beyond merely tracking environmental issues to change products, processes, their workplaces, and even their supply chains. To carry out their redesign efforts, they deploy various tools including: design for the environment (DfE), closed loop systems, industrial ecology, green building certification, supply chain audits."
}

Lubin and Esty (2010) subsequent framework suggests that winners i.e. those that achieve ecoadvantage, take a long term strategic perspective and develop trusted reputational brand values.

\section{How does Eco-advantage apply to small firms?}


SMEs are not homogenous entities that mimic larger organisations (Battisti, 2011). In 1999, Tilley (1999a) identified a significant gap in the literature exploring the response of small firms to the environmental challenge, especially literature with any real analytical enquiry. Twelve years on, the gap appears to remain, with relatively few new papers exploring the issue, notable exceptions being van Hemel and Cramer, 2002; Vernon et al 2003). Esty and Winston (2006) focus on large corporations but do acknowledge the SME context, recognising that developments in legislation and monitoring mean that more and more SMEs will be exposed to stakeholder pressure and legislative requirements and that, large customers evaluating their supply chains will impact upon SME suppliers. Salam (2011) finds pressure from trading partners, especially buyers, to be a significant predictor of manufacturers' proclivity to adopt green procurement. Esty and Winston (2006) go on to suggest that SMEs are well placed to adopt eco-advantage because they are more nimble and able to change, are a focus for innovation, and can serve niche markets as new stakeholder demands emerge.

For those who are convinced that SMEs cannot have much impact by adopting eco-advantage, Tilley (1999a) points out that the large number of SMEs in most economies results in a significant cumulative impact. In 1995, Groundwork estimated that SMEs collectively accounted for 70\% of industrial pollution in the UK (Tilley 1999a:239) and between 50\% and 80\% of waste generated (Cassells and Lewis, 2011). Tilley (1999a) acknowledged that SMEs need different solutions to change their environmental behaviours because of different organisational and management structures, characteristics of the owner/managers and resource limitations in terms of time, finance and skills. She finds that there is a gap between the aspiration of SMEs to become more sustainable and their actions towards doing so which is influenced by a number of drivers, such as education and training. Tilley (1999a) goes on to suggest that enabling small firms to change their environmental behaviour requires weakening of the resistant forces, such as their poor ecoliteracy, strengthening of the driving forces, such as effective research and preferably a combination of both to encourage a strategic response. Writing in 1999, however, there was no real evidence of Esty and Winston's (2006) proposition of setting this within a wider stakeholder context and seeking opportunity from small firm environmental improvement. In Tilley's later paper (1999b) a sustainable or ecology strategy was discussed, which involves a "fundamental rethink of all aspects of the business" (Tilley. 1999b:5). This categorisation could be aligned to Esty and Winston's later concept of eco-advantage (2006) and Chakraborty's (2010) concept of value-seeking strategy

In 1999, Tilley asserted that not many UK SMEs could be described as proactive, while very few firms of any description fell into the ecology strategy and there was little research or understanding of this approach. Research undertaken at the time suggested that small engineering and business 
services firms were likely to, at best, adopt a piecemeal approach to environmental improvements and that those made were likely to either focus on waste management or to involve changes made primarily for cost saving such as energy efficiency. Some firms however, had introduced changes to marketing and design, but very few had addressed issues of materials/resource efficiency or the impact of their premises (Tilley, 1999b).

Over ten years later, feedback from a UK survey undertaken by Cassells and Lewis (2011) shows that waste and transport are the main areas where SMEs impact upon the environment, and their response focused on activities to manage hazardous waste, reduce waste and packaging and increase recycling; while also aiming to reduce fuel and energy use, optimise distribution networks and minimise pollution. Erkko et al (2005) reported similar responses in Finland. More positively, and in contrast to Tilley's (1999) earlier research, the survey shows more firms getting involved with programmes to replace or reduce materials use, and build in repair or recycling into their product platforms. However, only one third of firms market their business based on environmental claims, the majority only 'to some extent' (Cassells and Lewis 2011:192). Many of the improvements identified were considered by the researchers to fall into the 'cost-saving' category of environmental improvements (although not necessarily appreciated as such by the owner/managers), placing them firmly in the short-term, cost saving 'downside' of Esty and Winston's (2006) model. For Chakraborty (2010: 12) some of the drivers too are cost saving initiatives: "[S]everal green initiatives like green purchasing, waste minimization, total quality management, customer-focused approach and continuous improvements are influencing most companies to go green.."

Cassells and Lewis (2011) suggest that many entrepreneurs are personally motivated to act on green issues but lack the business resource to implement long term changes. Size matters, and Cassells and Lewis (2011) found that medium firms (50-99 employees) were much more likely to have environmental policies and management systems, specialist staff and pass on their values and expectations to their suppliers. These findings are consistent with those of Dangelico and Pujari (2010) who found that sustainability plans or ethical codes were important to their sample of SMEs, selected because of their proven commitment to sustainability issues, and that these codes were also an aid to internal communication. In the short term relatively simple interventions can make a significant contribution. For example a programme called Netregs.gov.uk (www.netregs.co.uk) enabled SMEs in the mining and quarrying industry, to save an average $£ 4,000$ each per year, by accessing information and reducing compliance costs (AIRN, 2008). However, Preuss (2009) found that outsourcing council services gave little opportunity for SMEs to participate because of perceived lack of reward and confusing information, while SME tendering for local government work is inhibited by bureaucracy. (Thomson and Jackson, 2007). A further barrier found by Vernon et al 
(2003) was that many SME's believed that it was the local authority planners that were responsible for protecting the environment, not themselves. A number of barriers to sustainability are therefore evident in SMEs but, as Vargas and Rangel (2007) argue, innovation is a key competitive driver. Similarly, van Hemel and Cramer (2002:452) identified that "environmental aspects can function as an impetus for product innovation."

\section{Obstacles to SME adoption of eco-advantage}

Tilley (1999a) and Vernon et al (2003) suggested that small firms in manufacturing and service sectors still have difficulty identifying and acknowledging their environmental impact. However, buyer requirements are a leading driver for SME willingness to participate in green improvements, but willingness is also linked to resource and capabilities (Lee, 2010). Although a significant proportion of buyers' sustainability requirements of their SME suppliers are informal, rather than contractual, SMEs are reluctant/unable to pass these expectations upstream to their own suppliers (Jorgensen and Knudsen, 2006). Furthermore, Merritt (1998 cited in van Hemel and Cramer, 2002:452) found that "supply chain pressures have, as yet, had little or no significant influence on SME behaviour." Lack of resources and capability to introduce environmental improvements constrains SME innovation, but this combines with a general lack of strategic vision and a tradition of short-termism that is inherent in SMEs (Cassells and Lewis, 2011).

"The small firms ... indicated a willingness to become more environmentally responsible, but they currently do not possess the ability or the conditions to fully and holistically integrate the environment into their business practices and simultaneously maintain their economic survival. It could be argued, then, that small firms are only as sustainable as society will allow" (Tilley, 1999b:13.

Even in eco-literate firms, Dangelico and Pujari (2010) found that a barrier for SMEs lies in avoiding trade-offs between function, cost, quality and aesthetics of green products when measured against those of conventional products, compounded by a lack of awareness of the benefits of green products. In addition, Melnyk et al (2001) point to the mismatch between views and objectives of managers and skilled workers within firms implementing environmental design changes, although Jenkins (2009) suggests that SMEs should focus on their inherent positive qualities to help implement more socially responsible activities. Moreover as Salavou and Avlonitis (2008:970) argue, "more innovative products require greater efforts and resource commitments from the firm but are likely to have positive performance effects because they gain significant comparative advantages that secure adoption by customers." A view supported by Yeh-Yun Lin and Chen (2007:116) who believe that "real innovation success resides in the marketplace." 


\section{Methodology}

Voss et al (2002) advocate the use of case studies for theory development in operations management - as well as, to a lesser extent, theory testing - because case studies can account for both the physical and human aspects of organisations. In SME focused research multi-site research is a luxury, so in this instance multiple SMEs are selected as case examples to provide consistency and contrast, therefore supporting confidence in the validity and robustness of the findings (Yin, 2009; Eisenhardt, 1989). The approach of using multiple small cases is also a pragmatic solution to the issue of limited access and scope of information to small businesses, already described as "hard to reach" (Cassells and Lewis, 2011) and provides a grounding from which to develop a more reliable analysis (Eisenhardt, 1989).

The context for the cases is a European funded knowledge transfer project (the Project) which aims to support SMEs from the UK East Midlands to become more sustainable, and the embedded cases (Yin, 2009) represent a selection of the SMEs which are participating in the Project. The SMEs are from a variety of sectors but are predominantly small and all have expressed an interest in making changes within their business. The overall case is represented by the Project, which is on-going, and the sub-cases are developing as the SMEs progress through the process. Additional evidence and cases, are being added to the Project's case study databank, so the paper reports part of a longitudinal study. The research design has been informed by the work of Vernon et al (2003) and van Hemel and Cramer (2002) who both adopted phased qualitative methodologies when researching SMEs and eco principles. Initially, a literature review was undertaken along with the compilation of a database of SMEs based in the UK East Midlands, drawn from internal and external sources. The literature review was designed to assist in the formulation of the initial typology and provide the basis for the later phases of the study. Through promotional activities and a short email to the SMEs on the database, SMEs were invited to a launch event. No attempt was made to categorise the sample in advance of the launch event, in terms of industrial sector or any assessment of their innovativeness. At the launch event SME attendees were asked if they wished to have the opportunity to engage with the Project to address sustainability issues. Of the 80 attendees at the launch event, 35 responded positively. Of these, 15 of the initial respondents agreed to participate in the intervention and the research. Recognition of the potential degree of bias from this self-selection process was catered for in the final analysis and interpretation of the results. Indeed Vernon, et al (2003) found in their study on SME environmental practice, participants self-selected but this was pragmatically necessary. Not only one data source was relied on. Documentary evidence and separate interviews with the SMEs and the academics involved in the intervention were undertaken, in line with Yin's (2009) proposed portfolio of data gathering methods, in the form of meeting notes, project plans and research reports, company and competitor websites and email communications between SMEs and the academics. 
The interviews adopted a semi-structured format (Saunders et al, 2003) offering opportunity for exploration and probing of the data, while enabling the researcher to keep to a negotiated theme. The interviews were conducted in three phases- prior to, during and post intervention and used a protocol designed to investigate the interviewees' views and experiences. Questions related to the business background and perceptions of sustainability, objectives of the intervention, both predicted and unexpected business impacts/ benefits that resulted and how the experience would inform future behaviours. Interviews with the academics involved in the interventions, included questions on the processes and knowledge used in the intervention, barriers, outcomes for the business and other benefits. The two lines of enquiry facilitated access to differing perspectives and contributed to internal validity. Interviews were conducted individually and face to face, at the respondents' premises. Feedback of the preliminary findings from the study was disseminated in a focus group forum enabling the respondents to reflect on the results and to share views and experiences.

A profile (see Table 1) of each respondent was drawn up and checked for accuracy with the participants. The methodology employed was designed to explore the eco-advantage adoption process within the SMEs. The research was particularly interested in how the SME culture contributed to generating new ideas and innovations to solve the sustainability issues encountered. Specifically, the research method was used to:1) gain an understanding of the level of awareness of eco advantage and the benefits that adoption could gain 2 ) the capabilities required to adopt sustainability innovations and 3) to identify what issues emerged when eco-advantage was implemented by the SMEs.

\section{Limitations, validity and rigour}

In this research verification was sought by seeking SME approval of the individual case studies. Internal validity was provided by the replication logic (Yin 2009). Recordings of the interviews have been transcribed and notes from these and participant observation retained in a case study databank (Saunders et al, 2003) to facilitate standardisation across the interviews. A limitation noted is that the researcher was a member of the project team and known to some respondents. However, this has supported access to a hard-to-reach group and knowledge of the SMEs' activities is considered to be an advantage. Similarly, the potential bias in geographical location and respondent self-selection has been acknowledged.

Table 1 Profile of case companies and products/services

\begin{tabular}{|l|l|l|l|l|l|}
\hline Case & $\begin{array}{l}\text { Size } \\
\text { employees }\end{array}$ & $\begin{array}{l}\text { Age } \\
\text { yrs }\end{array}$ & Company type & Market & Green Product type \\
\hline 1 & $10-24$ & 58 & Furniture manufacturer & B2B moving B2C & Relative green \\
\hline 2 & $25-49$ & 42 & Plastics manufacturer & B2B moving B2C & Relative green \\
\hline
\end{tabular}




\begin{tabular}{|c|c|c|c|c|c|}
\hline 3 & $5-9$ & 10 & Exhibition equipment design/ build & $\mathrm{B} 2 \mathrm{~B}$ & Relative green \\
\hline 4 & $25-49$ & 33 & Household textiles manufacture & $\mathrm{B} 2 \mathrm{C}$ & Relative green \\
\hline 5 & $5-9$ & 11 & Architect & B2PS & Absolute green \\
\hline 6 & $5-9$ & 15 & Architect & B2PS & Absolute green \\
\hline 7 & $1-5$ & 6 & Fashion accessories designer & $\mathrm{B} 2 \mathrm{C}, \mathrm{B} 2 \mathrm{~B}$ & Relative green \\
\hline 8 & $1-5$ & new & Renewable energy generation & $\mathrm{B} 2 \mathrm{C}, \mathrm{B} 2 \mathrm{PS}$ & Absolute green \\
\hline 9 & $1-5$ & 10 & Renewable energy installation & $\mathrm{B} 2 \mathrm{~B}$ & Absolute green \\
\hline 10 & $1-5$ & new & Product design & $\mathrm{B} 2 \mathrm{C}, \mathrm{B} 2 \mathrm{PS}$ & Absolute green \\
\hline 11 & $1-5$ & 5 & Textile design & $\mathrm{B} 2 \mathrm{C}$ & Relative green \\
\hline 12 & $1-5$ & 4 & Jewellery designer & $\mathrm{B} 2 \mathrm{C}$ & Relative green \\
\hline 13 & $50-99$ & 60 & Theatre & $\mathrm{B} 2 \mathrm{C}$ & Relative green \\
\hline 14 & $10-24$ & 35 & Interior design/ make & $\mathrm{B} 2 \mathrm{C}$ & Relative green \\
\hline 15 & $5-9$ & 9 & Concrete product design/make & $\mathrm{B} 2 \mathrm{C}, \mathrm{B} 2 \mathrm{~B}$ & Relative green \\
\hline
\end{tabular}

Key to Markets: B2B: Business to Business; B2C: Business to Consumer; B2PS: Business to Public sector, including public funded social enterprises, housing associations, heritage organisations, etc.

\section{Results}

The research explores $15 \mathrm{SME}$ cases following short interventions in sustainable product and process design through a university knowledge transfer project. The cases have been analysed using a coding system, as suggested by King (2004) and the findings summarised into a coding table (Table 2) in terms predefined by theory and refined during the analysis in accordance with Miles and Huberman (1994). The cases cover a diverse range of SMEs, including ten micro-businesses, four small, and one of medium size. Size correlates with age - the small-medium businesses having been established from 35 to 60 years, while the micro-enterprises range from new start to 15 years old, but in spite of their maturity, respondents were mostly in the early stages of their journey towards being more sustainable. Of the sample, 11 SMEs are predominantly manufacturers, while the remaining four are service orientated. Eleven of the SMEs service or are targeting Business to Consumer Markets, and with the exception of the renewable energy and architect companies, all are delivering products/services classed as relative green. Using the data in Table 1, the results have been analysed and reported according to the research objectives identified.

Given their heightened awareness and 'self-selecting' sample inclusion, it is perhaps not surprising that several SMEs fell into Tilley (1999b) and Cassells and Lewis (2011) typology as proactive, having identified opportunities in the market for new innovations, new applications for more sustainable versions of their products, or to broaden the appeal of sustainable designs. An example is case 11 , who specifically asked to learn pattern-cutting skills to complement her existing technical capabilities and improve the marketability of her product. In implementing proactive ideas, an element of reaction is required, for example to comply with unfamiliar legislation. Examples include 
case 13 which has had to make compromised changes to their building in order to control energy use, within the constraints of occupying a listed property, and case 8 , which had to amend its business model for generating energy for the community in order to comply with legal requirements. Although considered pro-active and more aware, these cases also demonstrate eco-naïvity rather than Tilley's (1999a) 'eco-literacy'. One reason why so many firms might be considered proactive relates to the nature of their markets. Most are either selling direct to consumers or trying to establish new business-to-business markets and therefore not subject to the urgency to meet customer and legal compliance as suggested by Esty and Winston (2006), instead relating closer to van Hemel and Cramer's (2002) driver of commercial goals. One exception is case 3, which requested support to develop more sustainable exhibition equipment at the behest of its major customer, therefore fitting Tilley's reactive typology. Only two of the SMEs could be described as fitting the ecology model, both driven by specific social entrepreneurial influence in line with Cassells and Lewis (2011) and both working in a well-informed architectural professional field.

As far as drivers for change are concerned, the companies represent a range of influences. Interestingly, contra to Tilley's (1999b) findings, very few of the cases presented with cost-saving as a key driver, although in almost all cases it was an added extra. Some SMEs did approach the Project speculatively to access support for new innovations, notably cases 1, 7 and 12 , regardless of the sustainability priority, but have welcomed the introduction of this new objective. Awareness raising has added priority to other drivers, as Tilley (1999b) also found. The environmental driver as a main priority has been curiously under emphasised by SME participants in the Project, partly explained since the SMEs with the most obviously sustainable products or services have already made progress in this area, and were instead looking for support to consolidate and commercialise their innovations with technical or marketing support. Again, however, as an added extra for new innovations or new market opportunities the sustainability concept is welcomed - and in some cases associated with cost saving. In contrast, the influence of stakeholder groups, as proposed by Esty and Winston (2006) has been an important driver to the cases which represent social or community enterprises or which benefit a number of different customer/ client groups, such as the social housing architect, theatre and community energy cases. In addition, those businesses supplying public sector organisations are perhaps ahead of the game in sustainability issues, where, in contrast to the findings of Preuss (2009) and Thomson and Jackson (2007) it appears that opportunities have been created for SMEs through sustainable procurement and that this has prompted an early, initially reactive response, progressing towards proactive as illustrated by case 2 whose Local Authority customer/ stakeholder has been a major driver in encouraging the business to explore new products and markets. 
Market opportunity is a prominent driver and a feature of almost all cases whether they entail developing new products, verifying the beneficial properties of existing or upgraded products, marketing existing or new products to new or existing customers, or indeed marketing sustainable values as product extensions. This is illustrated by the jewellery design company who initiated a product to service shift as suggested by Maxwell and Vorst (2003). It would be hard to claim, however, that any of the case SMEs have the capability or resource to reach the brand-value model as defined by Esty and Winston (2006).

However, for the smallest firms, there is evidence that even modest growth enables greater management time to be devoted to awareness raising activities that can support the generation and implementation of new ideas. One micro-entrepreneur commented: "I thought long and hard about how I could have an [environmental] impact.... I've been able to attend more events and develop ideas since employing new staff." Others have technical skills but lack those in marketing and finance or vice-versa. The research finds that manufacturing focused SMEs are relatively cautious about their ability to manage their environmental impact - perhaps one step on from Tilley (1999a) and Vernon et al (2003) who suggested that such firms were in denial about the consequences of their practices. In contrast, the marketing focused firms were ambitious about their potential to make a difference, but lacked the eco-literacy to identify the areas in which they could have most genuine impact. Typical would be case 13, the designer of concrete fixtures and fittings, who's niche market products were unlikely to significantly reduce impact unless their (or their customers') brand exposure proved sufficient to influence widespread behavioural change.

While, according to Lee (2010) and Salam (2011), buyer pressure influences manufacturers' proclivity to adopt green practices, it is also found to be a driver towards seeking more formalised approaches to sustainability - atypical for SMEs according to Cassells and Lewis (2011). In addition, customer influence can also encourage SMEs to seek external support to complement their internal capabilities. Cases 3, 4, 5 and 6 all sought external and independent verification of their products to support marketing efforts. Even the larger companies in the sample clearly have difficulty in maintaining a balance of internal resources. The furniture company director identified time as a limiting factor and worked on his sustainable design project in evenings and at weekends, while the interior design company (case 14) lacked the business management skills to commercialise more sustainable products and processes and has since closed.

With regard to implementation issues, Legrand et al (2010) find a trade-off between the potential rewards for actions undertaken against the threat of penalties for failure to act. In the sample cases, 
the risk of inaction appears relatively low and a number of the cases use sustainability innovations to create market differentiation and first mover advantages, as found by Markley (2007). Whereas Esty and Winston (2006) argue for a more formalised analysis of downstream stakeholder and customer needs, in the sample understanding of the market tends towards gut feeling, and many of the interventions have incorporated a marketing angle to compensate for this endogenous capability gap. This supports SMEs to manage the 'upside' issues such as marketing and values (Esty and Winston 2006) and also develop a more strategic, results driven 'mindset'. The trade-off in adopting a proactive stance is also evident, however. In some cases, such as the accessories designer, there is clear evidence that product innovations are not cost-neutral and several of the SMEs, such as the furniture manufacturer, find themselves exposed to instability in the upward supply chain in terms of finding alternative materials and compatible manufacturing capability - partly because of the relatively small volumes and specialist materials concerned.

In summary, the results build on the work of Esty and Winston (2006) on 'eco-advantage', highlighting marketing, rather than compliance issues as a catalyst for change. The newly aware SMEs demonstrate a nascent inner confidence, espouse wider sustainable values and attempt to influence upstream and downstream practices in four dominant ways: use of alternative materials, enhancing recyclability, as defined by Sharma et al (2010), local sourcing, and product to service shifts in accordance with Maxwell and Vorst (2003). Obstacles include ephemerality of benefits as identified by Shearlock et al, (2000), and practicalities of implementing internal and supply chain innovations, often with very limited resources and endogenous capability gaps.

From the results above it is possible to derive a Model that encapsulates the implementation of eco advantage within the SMEs. The Model proposed reflects the contingent nature of the implementation process within the SME sector and the cumulative capability arising from both anticipated and additional outcomes during each intervention as reflected in the final two columns of Table 2. 
Table 2 Summary of case experiences and outcomes

\begin{tabular}{|c|c|c|c|c|}
\hline Case & Company type & Driver & Green Product Project and Eco-Advantage outcome & Added resource / capability \\
\hline 1 & $\begin{array}{l}\text { Furniture } \\
\text { manufacturer }\end{array}$ & Innovation & $\begin{array}{l}\text { Sustainable Sofa, including design, materials, construction. New } \\
\text { construction techniques. On-going marketing support. }\end{array}$ & $\begin{array}{l}\text { Technical, materials, prototyping, } \\
\text { marketing }\end{array}$ \\
\hline 2 & Plastics manufacturer & Stakeholders & $\begin{array}{l}\text { Concept testing, design and market research for new gardening product } \\
\text { to aid grow-your-own vegetables success. On-going marketing support } \\
\text { to enter B2C market. }\end{array}$ & Technical, testing, marketing \\
\hline 3 & $\begin{array}{l}\text { Exhibition equipment } \\
\text { design/ build }\end{array}$ & Stakeholders & $\begin{array}{l}\text { Developing alternative to one-off exhibition displays for customer } \\
\text { (white-goods brand). }\end{array}$ & Materials testing and verification \\
\hline 4 & $\begin{array}{l}\text { Household textiles } \\
\text { manufacture }\end{array}$ & Environmental & $\begin{array}{l}\text { Testing window dressings to establish benefits to energy use and } \\
\text { environmental control within the home. }\end{array}$ & Materials testing and verification \\
\hline 5 & Architect & Environmental & $\begin{array}{l}\text { Monitoring user and technical benefits of sustainable home. Includes } \\
\text { technical and social science research. }\end{array}$ & $\begin{array}{l}\text { End-product monitoring and } \\
\text { verification }\end{array}$ \\
\hline 6 & Architect & Environmental & $\begin{array}{l}\text { Monitoring user experience of retro-fitted social housing. Includes } \\
\text { technical and social science research. }\end{array}$ & $\begin{array}{l}\text { End-product monitoring and } \\
\text { verification }\end{array}$ \\
\hline 7 & $\begin{array}{l}\text { Fashion accessories } \\
\text { designer }\end{array}$ & $\begin{array}{l}\text { Market } \\
\text { opportunity }\end{array}$ & $\begin{array}{l}\text { Visual merchandising for retail outlet and expansion of own designed } \\
\text { product range. Includes guidance in product design and materials } \\
\text { sourcing; and support for retail and social media marketing, product to } \\
\text { service shift. } \\
\text { On-going spin-out business support. }\end{array}$ & $\begin{array}{l}\text { Technical support, prototyping, } \\
\text { marketing support }\end{array}$ \\
\hline 8 & $\begin{array}{l}\text { Renewable energy } \\
\text { generation }\end{array}$ & Environmental & $\begin{array}{l}\text { Developing water powered energy generation for local community. } \\
\text { Includes researching social enterprise business models, funding sources, } \\
\text { stakeholder generation. }\end{array}$ & $\begin{array}{l}\text { Business modelling, marketing, } \\
\text { logistics, finance. }\end{array}$ \\
\hline 9 & $\begin{array}{l}\text { Renewable energy } \\
\text { installation }\end{array}$ & $\begin{array}{l}\text { Market } \\
\text { opportunity }\end{array}$ & $\begin{array}{l}\text { System of solar power installation for industrial units. Includes business } \\
\text { model and finance support }\end{array}$ & Accounting and business model. \\
\hline 10 & Product design & Innovation & $\begin{array}{l}\text { Designing new type of wind power generator. Technical support to } \\
\text { refine and protect product design, prototyping and testing. }\end{array}$ & Technical \\
\hline 11 & Textile design & $\begin{array}{l}\text { Market } \\
\text { opportunity }\end{array}$ & $\begin{array}{l}\text { Improved design and fit of clothing products, wider product range. } \\
\text { Awareness of new media marketing. }\end{array}$ & Technical, social media marketing \\
\hline
\end{tabular}




\begin{tabular}{|l|l|l|l|l|}
\hline 12 & Jewellery designer & $\begin{array}{l}\text { Market } \\
\text { opportunity }\end{array}$ & $\begin{array}{l}\text { Developing workshop concept to enable customers to make products, } \\
\text { develop emotional attachment through the experience and reduce } \\
\text { consumption }\end{array}$ & Value change, marketing \\
\hline 13 & Theatre & Cost reduction & $\begin{array}{l}\text { Based in listed building, but needs to reduce running costs. Thermal } \\
\text { imaging and energy analysis, with follow-on recommendations for } \\
\text { remedial actions. }\end{array}$ & Technical \\
\hline 14 & Interior design/make & Cost reduction & $\begin{array}{l}\text { Process improvements to reduce waste and increase productivity. } \\
\text { Included value stream mapping, customer feedback, workshop } \\
\text { awareness raising. }\end{array}$ & Process improvements \\
\hline 15 & $\begin{array}{l}\text { Concrete product } \\
\text { design/make }\end{array}$ & $\begin{array}{l}\text { Market } \\
\text { opportunity }\end{array}$ & $\begin{array}{l}\text { Diversify product range, new uses and applications for lower density } \\
\text { concrete. Student project to design alternative products. }\end{array}$ & Design \\
\hline
\end{tabular}


The SME Sustainability Innovations Framework (Diagram 1) has at its centre the building blocks of initiation, development and learning, which reflect the intervention stages of first contact, planned action and outcomes as undertaken during the Project. This is essentially a logical, rational and structured process that becomes embedded in the SME, supported by the organisation's structure, information systems and management style in the process of enhancing eco-literacy (Tilley 1999a) and acting upon new found capabilities. Successful application of this foundation in terms of business performance will tend to re-enforce the adoption of the sustainability process and emphasise the need to develop further skills and knowledge to support the approach - hence a cumulative and more strategic process emerges (Esty and Winston 2006).

\section{Insert Diagram 1}

The Diagram reflects the findings of the descriptive processes discovered from this empirical study The study suggests that for the smaller scale SME in particular, the stimuli for these foundations take the form of a number of dominant drivers. Three processes appear to be extant in SMEs: cost, marketing and/or sustainability drivers. The value of the model is inherent in supporting the adoption of sustainability within SMEs, in terms of understanding, managing and supporting ecoinnovation and the effective achievement of eco-advantage. The model suggests that, while there is no one-size-fits-all solution, there is a recognised sequence of capability enhancement which can be both attractive and effective for micro and small businesses.

\section{Discussion}

The methodology adopted in the study did generate a rich picture of the issues involved in sustainability processes and the move to eco-advantage within SMEs. The results reveal the scope for SMEs to adopt more sustainable practices, encompassing innovations beyond environmental monitoring. Contra to Tilley's (1999b) assertion that SMEs are constrained in balancing economic and environmental performance, for some SMEs environmental change is seen as a vehicle to economic performance. Progress made since 1999 in this fast moving field, suggests that a new type of small firm has emerged in which environmental consciousness is more predominant. While this is seen as a way to generate opportunity, consistent with the findings of Dangelico and Pujari (2010), most of the SME respondents here are just starting on their journey towards achieving sustainability, unlike those in the earlier study. There is less emphasis on sustainable practices to reduce cost or comply with regulations or specifications, in line with van Hemel and Cramer (2002) and Erkko et al (2005) who both found that combining sustainability with commercial imperatives was the way 
forward, rather than reliance on environmental initiatives alone. Several of the case studies serve consumer markets, in which context customer requirements are often aspirant rather than specified.

While Vernon et al (2003) suggests it is a lack of awareness, or what Tilley (1999a) describes as ecoliteracy, that inhibits innovation, the sampled SMEs exhibit a range of awareness levels that potentially signals a newly aware SME culture, but one not necessarily paralleled by technical ecoliteracy. Only two cases appeared to be unaware and unconcerned about sustainability issues at the first point of intervention. The furniture manufacturer's interest was raised during a tour of product design workshops, while the jewellery designer failed to realise that her move from product towards a service orientation had a potential sustainability benefit. At the other extreme the architect companies would both describe themselves as eco-champions having previously worked on pioneering developments. Most SMEs were aware of sustainability issues, but not necessarily fully conversant with either the commercial, environmental or resource implications of their ideas.

What is clear however, is that for SMEs to effectively progress towards achieving true eco-advantage a multitude of benefits accrue, which include increased capability in a number of areas - product design, recycling, materials use, production efficiency, marketing communications, marketing planning, financial planning and human resource management are all represented in combination by the 15 cases. The findings therefore concur with those of Tilley (1999a) in that improving ecoliteracy in conjunction with positive interventions such as effective research can encourage a strategic response. However, the range of projects undertaken by the sample SMEs demonstrates a broad interest in sustainability issues beyond those initially identified by Tilley (1999b) and later by Erkko et al (2005) and Cassells and Lewis (2011). The increased interest in innovations based on product life-cycle and materials moves these SMEs closer to Vargas and Rangel (2007) and van Hemel and Cramer's (2002) view that sustainability can foster innovation and in turn competitive advantage. The marketing of their sustainability credentials is also of growing interest, building on Cassells and Lewis's (2011) findings and evidenced by the popularity of activities organised to support this approach. Hence, the decision to adopt what Lynne (2008) pragmatically defines as equal concern with commercial and environmental issues and care for customers as well as sustainability is, for the sample SMEs, inherent with compromise. The research identifies the benefits to SMEs of accessing broader and external capabilities, thus addressing their lack of ecoliteracy in order to make better informed decisions relating to both costs and opportunities and encouraging a gradual shift in overall values and strategy. This combined approach is exemplified 
by case 1 which has made the transition from an inactive strategy (Tilley 1999b) to become a proactive sustainability advocate, with better products, processes and market opportunities.

As small, rather than medium sized businesses, the sampled SMEs illustrate the contrast and limitations of their inherent capabilities, referred to by Tilley (1999a) in terms of differing organisational and management structures, characteristics of the owner/managers and limited time, finance and skills. The arising internal conflict, consistent with Melnyk et al (2001) highlighted contrasting views of managers and technical staff while implementing environmental design changes. In contrast, the plastics manufacturing company, case 2, regularly made a point of including production and business managers in project meetings, supporting Pujari's (2006) notion of cross functional co-ordination as a success factor.

According to the literature (Tilley 1999b), where cost drivers prevailed, the drive to save costs stimulated innovations, which then offered market opportunities and led to a social /environmental impact. The primary initiator of the process is cost or more precisely the perceptions of such cost pressure, although cost as an initiator was rarely present in the sample cases. Similarly few SMEs sought to engage in the sustainability process simply as a 'good thing' that might yield positive results in the future and none saw the process as one that would be initiated and informed by a systematic market research process irrespective of how this might be defined within the SME context. However, there was a common, though largely unsubstantiated perception that market opportunities could be facilitated by the innovation process and embedding sustainability values, and market opportunity therefore became the main driver in several cases. For those SMEs driven initially by the sustainability impact, innovation to realise their objectives and then market opportunity to commercialise these tended to follow. Capacity for cost savings was considered contingent on the perceived market response - reflective of the niche market in which such SMEs position themselves and consistent with Esty and Winston (2006).

The resource constraints previously identified contrast with views propounded by Doyle (1998) and Esty and Winston (2006) that SMEs are nimble, able to quickly implement change and respond to niche market opportunities. While Doyle's (1998) assertion that growth constrains sustainable innovation is plausible, the cases suggest that the resource and capability constraints observed are, at least in very small firms, a dominant limiting factor constraining the effectiveness of the nimble response and the evidence on which trade-off choice is based. For example, having developed and tested an innovative, sustainable product, case 2 is dependent on better market knowledge to determine the quality/materials/ cost input of their end product. 
There is, therefore, a need to identify multiple points on which a firm can achieve a sustainable advantage: including cost saving, environmental impact reduction, stakeholder values, product or service, added-value, innovation and market opportunity - with firms required to develop capability in all areas to some extent. These aspects may be more or less important in different markets and contexts as our results show. For example, the case study companies are predominantly niche market seekers for whom product and service quality and business value is more important than cost efficiency. Firms targeting mass market, or competing for business tenders may have different objectives, as found by Dangelico and Pujari (2010). The paradigm of eco-advantage however, suggests that all aspects should be addressed in pursuit of compromise and mutual gain (van Hemel and Cramer, 2002).

This leads the authors to surmise that there may be an effective sandcone of 'Cumulative Capability' (CC) associated with business sustainability improvements in line with that proposed by Ferdows and De Meyer (1990) in operations management. While most CC models propose that quality is the bedrock of the cone, there are multiple variations on this theme (Flynn and Flynn, 2004) and no consensus of the sequential development. In terms of eco-advantage one might propose that environmental/ social impact is the foundation, followed by cost saving, product/process innovation, market opportunity and topped by stakeholder value but the experience of Tilley (1999b) and Cassells and Lewis (2011) combined with the case study analysis suggest more than one variation on this theme, with a cost driver being an alternative starting point. This proposition is a potential mechanism for firms to reach the strategic aspect of Esty and Winston's (2006) model but requires further research for verification.

\section{Implications and Conclusions}

In contrast to prior studies, this paper emphasises the experiences and implementation issues of the SMEs, rather than their products, when starting out on their journey to embrace sustainability. The cases suggest that there is a capability gap in terms of managing the resource needed to commercialise SMEs, while achieving economic and environmental/ social sustainability. Very few firms could be described as true value seekers or having reached eco-advantage. So while the case companies are moving into Esty and Winston's (2006) 'upside' it is apparent that their activity is 
based mainly on the 'short-term' side of the eco-advantage model. In contrast to Dangelico and Pujari (2010) very few of the SMEs have progressed to the long-term or strategic stage, either in terms of perceived risk, or developing brand reputation, which would classify them as 'dreamers' rather than 'winners' in Lubin and Esty's (2010) updated model. Contrary to previous research, stakeholder influence was important to the SMEs. For those SMEs who supplied the public sector, sustainable procurement practices had created opportunities and a catalyst for sustainability innovations. In consumer markets, target market demands had highlighted the need for SMEs to become increasingly aware of the importance of marketing their sustainability credentials.

It seems evident that the SMEs are open to adopting the same sense of importance about sustainability and innovation for their business as intrapreneurs in larger organisations. There is also common ground between them in relation to the contextual factors or drivers of the process and the need to generate a supportive culture within the organisation. The differences begin to appear when exploring the nature of the processes within the smaller SME and the larger business. The size of the SME constrains their influence on their own suppliers, as for example, they are only purchasing relatively small quantities of materials. Larger companies with established procurement protocols can ensure that their suppliers mirror their own sustainability requirements. Size also impacts upon capabilities in terms of number of staff and time available for sustainability initiatives. For the SME it seems that market opportunity, sustainability, innovation and change management are a single integrated process rather than discrete elements undertaken by different individuals or groups within the organisation. An implication of this is the need to embody the different knowledge, skills and competencies associated with each of these elements in a single person, possibly the SME owner themselves. There is thus a willingness to change, to adopt eco-advantage but the inherent resource capabilities to change are limited; with the sustainable innovation, potentially lost without guided intervention. It is not their lack of awareness that is the constraint, but rather the SME owners' cautious behaviour about the influence that they as individuals can have on sustainability.

The paper informs the emerging debate on sustainability in SMEs, providing a rich source of data to enhance the provision of business support and knowledge transfer activities, where a more holistic and customised approach is required to realise the real benefits accrued from implementing sustainable improvements, to achieve environmental and economic success and influence and satisfy stakeholder value. This is an emerging field and the paper proposes a Model for evaluating environmental progress towards firm capability, which could influence strategic planning and future intervention for businesses, especially SMEs. The Model recognises heterogeneity of SMEs in that they will all have a different starting point, positioned along a continuum of sustainability awareness. The components of the Model emerge from the primary data collection and identified the key stages

Comment [OL2]: I assume this should be without not 'with'. Opposite meaning but this makes more sense. 
that SMEs can pass through in the sustainability adoption process. The Model should facilitate more effective policy and strategic interventions by increasing the awareness and understanding of the SME context. It is recognised that although the illustration is suggestive of a linear process, in reality bi-directional progress is possible.

The overall project case reinforces Tilley's (1999a) model by demonstrating that business support and awareness raising can help to overcome resistance factors, while broader capability (education and training) at least in part, helps to introduce driving forces, demonstrated by the cases which start with a specific problem, in turn leading onto wider scale changes and value shift. It also demonstrates the interface between sustainability, innovation, marketing and organisational learning and suggests that a contingency approach best serves the needs of the SMEs. As van Hemel and Cramer (2002) argued environmental innovations have to be supported by other social and economic factors. The key contingency variables include sector, size, competitive position, strategic aspirations and organisational culture. For example, those who grew and took on staff were able to develop increased awareness about sustainability issues.

Further work is required to develop the conceptual model proposed and to identify the constructs and measures necessary to develop a useful toolkit. This should include longitudinal study, of which very few exist in this emerging field. Project engagement with the case study firms provides an opportunity to engage with these SMEs over a longer period of time. Survey data would also support generalisation and give a more robust view of the drivers and stage of development of a wider sample of firms. It would be especially advantageous to explore these issues with medium sized firms from different sectors. Two final thoughts concerning the interface between sustainability and innovation in the smaller organisation are worthy of note. There appears to be a strong case supporting the need for the development of metrics within the SME sector to gauge the real impact of sustainability, despite Erkko et al (2005: 810) arguing that the precedent of the triple bottom line approach has overtaken the development of "parameters for eco-efficiency." Few of the SMEs were able to quantify in any sense the benefits of investment in sustainability other than a view that it was becoming necessary to compete successfully. Secondly, prescribed principles and practices may need revision to reflect the more contingent nature of their application within the smaller SME.

\section{References}

Battisti, M. and Perry, M. (2011) "Walking the talk? Environmental responsibility from the perspective of small-business owners" Corporate Social Responsibility and Environmental Management May/Jun, Vol. 18 Issue 3, pp. 172-185 
Baumann, H., Boons F., and Bragd A. (2002) Mapping the green product development field: engineering, policy and business perspectives Journal of Cleaner Production Vol. 10(5) pp. 409-425 Cassells, S. and Lewis, K. (2011) "SMEs and Environmental Responsibility: Do Actions Reflect Attitudes?" Corporate Social Responsibility and Environmental Management. Vol.18, pp. 186-199

Chakraborty, S., (2010) "Concise Chronology Road Map of Evolving Green Supply Chain Management Concepts: a review", IUP Journal of Supply Chain Management, Vol. V11 , No.4 pp.725

Crittenden W., Ferrell L., Ferrell O. and Pinney C. (2011) "Market-oriented sustainability: a conceptual framework and propositions" Journal of the Academy of Marketing Science Feb 2011, Vol. 39 Issue 1, pp.71-85

Dangelico R. and Pujari, D. (2010) Mainstreaming Green Product Innovation: Why and How Companies Integrate Environmental Sustainability Journal of Business Ethics, Vol. 95(3) pp. 471486.

Dangelico R. M. and Pontrandolfo, P. (2010). From green product definitions and classifications to the Green Option Matrix Journal of Cleaner Production, Vol.18(16-17) pp. 1608-1628.

Doyle, P. (1998) Marketing and Management Strategy, 2nd Edition, Prentice Hall: Hemel Hempstead

DTI and CBI (1994) Competitiveness - How the Best UK Companies are Winning, Cm 2563 The Stationery Office, London

Eisenhardt, K. (1989) "Building Theories from Case Study Research", The Academy of Management Review Vol. 14, No. 4 pp. 532-550

Erkko S., Melanen M. and Mickwitz P. (2005) "Eco-efficiency in the Finnish EMAS reports- a buzz word?" Journal of Cleaner Production Vol.13 pp.799-813

Esty, D. and Winston A. (2006) Green to Gold, Wiley: New Jersey

Ferdows, K. and DeMeyer, A. (1990) "Lasting improvements in manufacturing performance: in search of the new theory" Journal of Operations Management Vol.9, pp. 168-184.

Flynn B, and Flynn E. (2004) "An exploratory study of the nature of cumulative capabilities" Journal of Operations Management, Vol.22 pp.439-457 
Henry, J. and Walker D. (1991) Creative Management. SAGE Publications: London

James, P., (1997) "The Sustainability Circle: a new tool for product development and design" Journal of Sustainable Product Design 2: 52:57, http://www.cfsd.org.uk/journal09

Jenkins H. (2009) "A Business Opportunity Model of Corporate Social Responsibility" Business Ethics, Vol. 8, No.1, pp.21-36

Jones, E., and Harrison, D. (2000) "Investigating the use of TRIZ in Eco- innovation" TRIZCON2000 Conference Proceeding. Altshuller Insititute www.trizjournal.com/archives/2000/09/6/index

Jorgensen, A., and Knudsen, J. (2006) "Sustainable competitiveness in global value chains: how do small Danish firms behave?" Corporate Governance, Vol. 6, No.4 , pp.449-462

King, N. (2004) "Using interviews in Qualitative Research", in Cassell C. and Symons G., (eds) Essential Guide to Qualitative Methods in Organisational Research, Sage: London pp. 13-33

Lee H. (2010) "Don't Tweak Your Supply Chain - Rethink It End", Harvard Business Review October 2010, pp.63-69

Legrand, W., Sloan, P., Simons-Kaufmann C., and Fleischer, S. (2010), "A Review of Restaurant Sustainable Indicators" in Chen J., Advances in hospitality and leisure Volume 6 [ebook] Bingley: Emerald, pp. 167-184

Lubin D.A.and Esty D. C. (2010) “The Big Idea”, Harvard Business Review, May 2010, pp.42-51

Lynne G. (2008) "Green to Gold: Business and Industry Moving Onto the Eco-path", Cornhusker Economics 30.1.08, University of Lincoln, Nebraska.

Maddock M. and Vitn R., (2010), "Going Green's Unexpected Advanatage" Business Week.com 2/3/2010, p.9

Markley M. and Davis L. (2007) "Exploring competitive advantage through sustainable supply chains" International Journal of Physical Distribution and Logistics Vol.37, No.9 pp.763-774

Maxwell D. and van der Vorst R. (2003) "Developing Sustainable Products and Services" Journal of Cleaner Production, Vol.11 pp.883-895 
Melnyk, S., Handfield, R, Calatone, R. Curkovic (2001) "Integrating Environmental Concerns into the Design Process: The Gap Between Theory and Practice" IEEE Transactions on Engineering Management, Vol.48, No. 2 pp. 189-208

Merritt J.Q. (1998) "EM into SMEs won't go ?Attitudes, awareness and practices in the London Borough of Croydon" Business Strategy Environ 7 pp.90-100 cited in Van Hemel . and Cramer J. (2002: 452)

Miles M.B. and Huberman A.M. (1994) Qualitative data analysis: an expanded sourcebook 2nd edition Sage Publications: London

Preuss L. (2009) "Addressing sustainable development through public procurement: the case of local government" Supply Chain Management: An International Journal Vol.14, No.30 pp.213-223

Pujari, D. (2006) "Eco-innovation and new product development: understanding the influences on market performance"' Technovation Vol. 26, No. 1, pp. 76-85

Salam M.A. (2011) "Creating Sustainable Supply chain through Green Procurement" International Journal of Business Insights and Transformation Vol.3, No.3 pp.83-89

Salavou H. and Avlonitis G. (2008) "Product innovativeness and performance: a focus on SMEs" Management Decision Vol.46, No. 7 pp.969-985

Saunders, M., Lewis, P., and Thornhill, A. (2003) Research Methods for Business Students, $3^{\text {rd }}$ ed, Pearson Education: Harlow

Scholz, R. W. and Tietje, O. (2002) Embedded Case Study Methods: Integrating Quantitative and Qualitative Knowledge. Sage Publications Inc: : London

Seuring S. and Muller M. (2008) "From a literature review to a conceptual framework for sustainable supply chain management" Journal of Cleaner Production Vol.16 pp.1699-1710

Sharma, A., Iyer G. R., Mehrotra, A. and Krishnan R. (2010) "Sustainability and business-tobusiness marketing: A framework and implications" Industrial Marketing Management 39 pp.330341

Shearlock, C., Hooper, P. and Millington, S. (2000) "Environmental Improvement in Small and Medium Sized enterprises", Greener Management International , p.50

The Aggregates and Recycling Information Network (2008) http://www.aggnet.com/news/environmental-law-website-to-benefit-smes Sept 2008 
Thomson J. and Jackson J. (2007) "Sustainable procurement in practice: Lessons from Local Government" Journal of Environmental Planning and Management Vol.50, No.3 pp.421-444

Tilley, F. (1999a) "The Gaps Between the Environmental Attitudes and the Environmental Behaviour of Small Firms" Business Strategy and the Environment Vol.8 pp. 238-248

Tilley, F. (1999b) "Small-Firm Environmental Strategy: The UK Experience," Greener Management International Issue 25 pp.67-80 Greenleaf Publishing Ltd. GMI 25 Spring

van Hemel C. and Cramer J. (2002) "Barriers and stimuli for ecodesign in SMEs" Journal of Cleaner Production Vol.10 pp.439-453

Vargas D.M. and Rangel R.G.T. (2007) "Development of internal resources and capabilities as sources of differentiation of SME under increased global competition:a field study in Mexico" Technological Forecasting and Social Change Vol. 74, No.1 pp.90-99

Vernon J., Stephen E., Pinder D. and Kaja C. (2003) "The greening of tourism micro-business: outcomes of focus group investigations in South East Cornwall" Business Strategy and the Environment Vol. 12 pp.49-69

Voss C., Tsikriktsis N. and Frohlich M. (2002) Case Research in Operations Management; International Journal of Operations and Production Management, Vol. 22 / 2 pp. 195-219

Wilson E., Bunn M., and Savage G. (2010) Anatomy of a social partnership: A stakeholder perspective, Industrial Marketing Management, Vol. 39, No 1 pp.76-90

Yeh-Yun Lin C. and Yi-Ching Chen M. (2007) "Does innovation lead to performance? An empirical study of SMEs in Taiwan" Management Research News Vol.30, No.2 pp.115-132

Yin R.K. (2009) Case Study Research: design and methods, 4th Edition. Sage Publications Inc:: California 